\title{
Multilingualism at South African universities: a quiet storm
}

\author{
Venitha Pillay ${ }^{1 *}$ and $\mathrm{Ke} \mathrm{Yu^{2 }}$ \\ ${ }^{1}$ Education management and policy studies department, University of Pretoria \\ ${ }^{2}$ Democracy, governance and service delivery unit, Human Sciences Research Council, Pretoria \\ *Corresponding author, email: vpillay@up.ac.za
}

\begin{abstract}
This article seeks to reinforce the urgency for a multilingual academy in South Africa. It draws on recent quantitative data to unpack the dramatic decline of language enrolments and graduates of the 11 official languages. We explore the racial patterns in enrolments in the 11 official languages, given the scarcity of recent research articles that offer a quantitative comparison of the patterns of enrolment in this regard. We show that that while post-apartheid South Africa has seen a continuous rise in the popularity of English and Afrikaans, this has happened at the expense of all other official languages. We are mindful that the language policy in South Africa has political currency, which is not echoed in practical implementation. We suggest that while universities cannot ignore the politics of policy, it is the politics of practice in the form of what students choose to study that plays out in higher education institutions across the country. Our purpose therefore is to offer some insight into such practice. We argue that universities, in asserting their 'public good' mandate, should not be guilty of aiding and abetting the decline in indigenous languages by prioritising an efficiency mindset instead of a social justice one.
\end{abstract}

\section{Introduction}

We write this article not as linguists but as higher education practitioners. The critical importance of multilingualism at South African universities is signalled in the Linguistics and Education Special Issue 24 (2013) devoted to this concern and in the special issue of Language Matters: studies in the languages of Africa (45(3), 2014) devoted to the politics of language in Africa in which all the articles, save one, focus on language matters in South Africa. The quantitative data used in this paper is extracted from research conducted for the ASSAf on the state of humanities education at South African universities. To date much of the research on the status of the 11 official South African languages is qualitative with very limited quantitative insights available (Madiba 2013; Rudwick and Parmegiani 2013; Turner and Wildsmith-Cromarty 2014). In this paper our intention is to complement and extend the qualitative research on the challenges of implementing multilingualism at South African higher education institutions (HEls) through the presentation of a quantitative picture of undergraduate enrolments and graduations for the 11 official languages in SA.

We begin with a brief institutional policy overview aimed only at corroborating the extensive research done by Madiba (2013) and Turner and Wildsmith-Cromarty (2014) in this regard. We then present quantitative data on enrolments and graduations. We focus only on undergraduate patterns of enrolment and graduation because it is at the undergraduate level that dramatic numeric shifts are more evident (Pillay and Yu 2010). In an earlier paper (Pillay and Yu 2010) we showed that the loss of enrolment in the discipline of languages, linguistics and literature at undergraduate level is more severe (has shrunk by $27.68 \%$ ) than the loss at postgraduate level $(7.82 \%)$. In previous research on humanities education in South Africa we also showed that language is the most troubled discipline of all humanities disciplines (Pillay and Yu 2010).

We focus on the dramatic decline of language enrolments and graduates in each of the 11 official languages as a signal to universities to register the urgency for a multilingual academy. We explore racial patterns in enrolments in the 11 official languages, given the scarcity of recent research articles that offer a quantitative comparison of the patterns of enrolment for undergraduate language study. We note too that, in some instances, due to falling numbers, programmes in African languages 
have been phased out. For example, in 2010 isiXhosa was phased out at UCT, at the University of Johannesburg the degree in isiZulu for non-mother tongue speakers was terminated and a similar situation prevailed at the University of the Witwatersrand (Wits) (Turner 2012: 29). We are mindful that the language policy for higher education institutions has political currency and is often perceived to be the politically correct thing to do but is not echoed in practical implementation (Foley 2002; Cele 2004; Mwelwa and Spencer 2013; Rudwick and Parmegiani 2013; Turner and Wildsmith-Cromarty 2014). We are mindful too of the now clichéd gap between policy and practice and do not attempt to read this data as yet another example of this yawning gap. We suggest that while universities often 'play the policy game' for the sake of appearances, it is the politics of practice in the form of what universities offer and what students choose to study that is critical for the future of multilingualism. We show that the available data points to a looming crisis for the future of multilingualism at South African universities. We argue that universities in asserting their 'public good' (Marginson 2011) mandate should not be guilty of aiding and abetting the decline in indigenous languages by prioritising an efficiency mindset instead of a social justice one. As such there is a danger in playing politics through institutional language policies that are paper thin and which turn a blind eye to declining student numbers in enrolments and graduations in indigenous languages. In sum we make a call for concerted action in the form of practical implementable and action-oriented policies aimed at building a multilingual higher education landscape.

\section{Playing the policy game}

There have been a number of qualitative research articles and studies that speak to the issues of power, policy and practice with respect to the language landscape in South Africa since democracy in 1994 (Narismulu 2001; Foley 2002; Cele 2004; Van der Walt and Brink 2005; Balfour 2007, 2010; Coetzee-van Rooy 2012; Rudwick and Parmegiani 2013; Turner and Wildsmith-Cromarty 2014). These writers, among others, agree that post-apartheid South Africa has seen a steady rise in the popularity of English, and that this happened at the expense of the other official languages. At the same time there is also evidence that Afrikaans is a relatively 'safe' language as there have been no significant downward shifts for this language. Indeed, the quantitative data we offer verifies this claim and even shows increased interest in Afrikaans (see Figure 1).

In discussing language policy frameworks at South African HEls we use the extensive review offered by Turner and Wildsmith-Cromarty (2014), who summarise the language policies of five previously white South African universities. In sum they show that institutional commitment to multilingualism is frequently limited to public notices and signage and is inscribed in policy that sets multilingual teaching and learning goals for the future, with little if any immediate implementation plans. The exception has been the University of KwaZulu-Natal which 'has been driving an aggressive

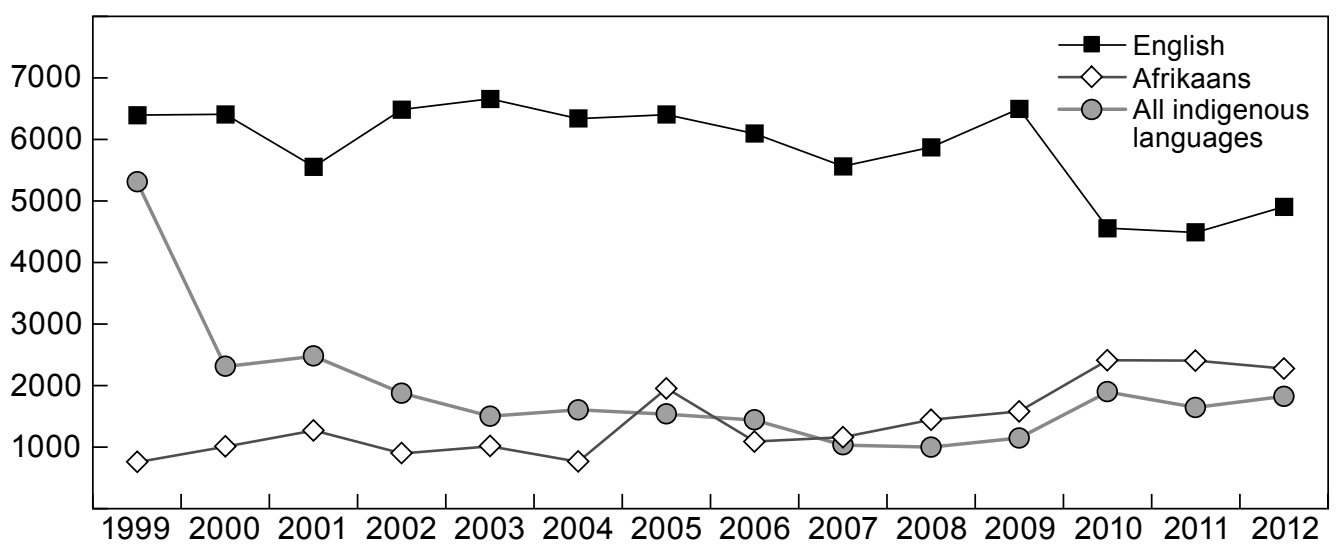

Figure 1: Undergraduate enrolment for Afrikaans, English and all indigenous languages 
language policy' making isiZulu a compulsory subject for all non-African language speaking students (Turner and Wildsmith-Cromarty 2014: 301). Response to the policy has been controversial and contradictory. While Rudwick and Parmegiani (2013) point to positive responses, Moodley's (2010) portrayal of the planned policy suggests the opposite.

The ultimate goal at UKZN is to provide teaching and learning in isiZulu and English (NdimandeHlongwa et al. 2010: 349). Balfour (2010) describes the second phase of the plan from 2019 to 2029, which envisages staff and students developing appropriate writing skills in English and isiZulu in their discipline. It is therefore envisaged that isiZulu will become part of the fabric of identity of the institution (Balfour 2010: 298). However, as Turner and Wildsmith-Cromarty (2014) point out, the university is a long way from there and the desire among isiZulu speakers to study in English as opposed to isiZulu is likely to militate against this eventuality.

In keeping with making isiZulu part of the demographic of UKZN, the Provincial Education Department has undertaken to replace Afrikaans with isiZulu as a second language in schools in the province (Balfour 2010: 299).

Madiba's (2013) research into language policy and implementation at the University of Cape Town is heartening and shows unequivocal institutional commitment to a multilingual future for the institution. According to a report of the Curriculum Working Group, English is the medium of instruction at the institution. ${ }^{1}$ However, the university has taken seriously the imperative to prepare students to participate in a multilingual society. Given that more than $80 \%$ of the student population are either English, Afrikaans or isiXhosa first language speakers, the university has decided to focus on strengthening isiXhosa as the African language that is promoted at the institution and, as Turner and Wildsmith-Cromarty (2014) point out, the institution has seriously committed to using African languages as auxiliary media of learning. Furthermore, students in Health Sciences and Medicine have to complete compulsory language courses in either isiXhosa or Afrikaans. The Multilingual Concept Learning Literacy project initiated by the Multilingualism Education Project aims to enhancing the lexicons of specific learning areas (Madiba 2013: 391).

In an in-depth study of language provision at the University of Stellenbosch, Leibowitz and van Deventer show that Afrikaans remains a central symbol of identity at the institution and that English and Afrikaans are the main languages of teaching and learning with Afrikaans being the 'default language of undergraduate leaning and instruction' (2007: 91). The policy also states that where possible, isiXhosa will be used as a language of external communication. A similar situation prevails at the University of the Free State, which is described as a dual-medium institution (English and Afrikaans) with 'commitment to a third language', Sesotho (Balfour 2010: 297). The official language policy of UFS developed in 2003 records a commitment to 'promote Sesotho as a language of science' and is taken into account 'insofar as this is reasonably practicable'. ${ }^{2}$ The introduction of English at previously Afrikaans institutions like Stellenbosch and the University of the Free State has led to what Balfour describes as a 'lively and sometimes factious debate...concerning the hegemony of English' (2010: 296).

Although Hill (2009) offers some insight into the efforts made towards academic bilingualism at the Nelson Mandela Metropolitan University (NMMU) the institution has made no significant or sustained effort towards implementing such bilingualism. Further, there seems to be no evidence of a discussion on the inclusion of an African language at NMMU. Of greater concern is the University of Pretoria, the largest contact university in South Africa. According to Van der Walt and Brink (2005: 836) 'multilingualism is not seen as a "selling point" for the university'. In the main, students may elect to take classes in English or Afrikaans, depending on their language proficiency. Aside from providing signage in English, Afrikaans and Sesotho, the university has said little and done little to make multilingualism a vibrant aspect of academic life (Van der Walt and Brink 2005).

In sum, we suggest that the challenge set out by the Minister of Higher Education in April 2011 that all university students have to learn an African language as a condition for graduating has not been adequately taken up by universities in South Africa, with many of the large universities in South Africa casually flirting with language policy with no real intention to commit to a plan of action. Perhaps the exceptions may be UKZN, UCT and Rhodes University, the latter of which integrates the study of isiXhosa into a number of professional degrees including Law, Pharmacy Education and Journalism 
(Turner and Wildsmith-Cromarty 2014). Of concern is the public and institutional reticence to adopt and implement what is arguably a valuable policy programme designed to achieve its goals over a 20-year period (Balfour 2010). In offering the quantitative data below, we point to the dire situation of the indigenous languages of South Africa.

\section{Methodology}

The data used in this paper is drawn from a larger data set on numeric trends in humanities education in South Africa. Higher Education Management Information System (HEMIS) data (1995-2012) for enrolment and graduation in undergraduate humanities faculties were obtained from Department of Education officials. It is to be noted that only data from 1999 onwards are included in this analysis because institutions across the country offered a vast number and complexity of qualifications prior to 1999 . We focus on undergraduate patterns of enrolment and graduation, as the most significant movements of students occurs at this level and that the number of postgraduate enrolments and graduations are small and numeric changes in this regard are minor. Further, it is at the undergraduate level that dramatic numeric shifts are most evident (Pillay and Yu 2010).

Raw HEMIS figures were tallied and translated into comparable graphs. This article therefore plots the trends in undergraduate enrolment and graduation across the 11 official languages. Because the numbers for individual indigenous languages are numerically too small to compare with either Afrikaans or English, all the figures below for all the indigenous languages are first compiled as one block item in the comparison with Afrikaans and English. We do so at the risk of Cele's (2004) criticism, which specifically makes a call to not 'lump' the indigenous languages together. In other words, the number for all indigenous languages would first appear by its sum. This would then be followed by the graphs indicating the respective trend of each of these indigenous languages. It is also to be noted that all figures presented in this article represent numbers for all SA higher education institutions, rather than that of any individual $\mathrm{HEI}$.

\section{Conceptual platforms}

In developing a conceptual entry point into understanding the numeric data offered here, we turned to recent qualitative research on language in South Africa. We focused, on the arguments presented by Cele (2004) in a paper titled: 'Equity of access" and equity of outcomes' challenged by language policy, politics and practice in South African higher education: the myth of language equality in education' and those of Turner and Wildsmith-Cromarty (2014) with respect to language policy planning. Cele makes the point that language inequality in South Africa persists despite constitutional language equality and that there are no convincing indicators of this changing (2004: 41; see also Foley 2002).

Cele (2004) strongly rejects the lumping together of all indigenous languages under the banner of indigenous languages and calls for a recognition of their 'sovereign individual identities' (2004: 50). In taking up this point we posit that it is possible to be fluent enough in an indigenous language to allow people to engage with a wider section of society and to practise equality of languages, without waiting for indigenous languages to be 'developed'. In so saying, we take Gao's (2009) point that, in the globalised world, children are increasingly multilingual. Gao (2009) interviewed Korean children in China and found a strong multilingualism linked to their understanding of identity. Indeed one of her respondents says 'I am not pure Korean, not pure Chinese. I can speak both Korean and Chinese, I feel there are two worlds in my life: one is Korean and the other is Chinese' (2009: 529). We use Cele's arguments about language equality to understand and explain some of the data patterns that emerge.

Turner and Wildsmith-Cromarty (2014) make a strong case for the value of acquisition and usage planning as viable points of entry for higher education institutions to reshape the linguistic fabric. Acquisition planning refers to language-in-education and makes provision for the learning of various official and national languages, while usage planning refers to the extended use of a language into new domains (Turner and Wildsmith-Cromarty 2014: 297). The data that follows points to the absence of decisive acquisition planning among universities. No clear inferences may be made from the data below with respect to usage planning. However, the institutional policy frameworks, or indeed their absence, described above suggests limited usage planning as well. 


\section{Study pattern for Afrikaans, English and all indigenous languages}

Figure 1 provides data on the undergraduate enrolments for English, Afrikaans and the indigenous languages. A number of observations can be made from Figure 1. The undergraduate enrolment for English has been relatively stable over the years, and not surprisingly it remains the most popular language subject among all the 11 official languages in SA, outstripping all other official languages by a great margin. That the popularity of English has far outstripped any of the other ten languages is well documented and may be explained by its global stature and its economic currency. This situation persists despite the fact that only 9.6 million of the population list English as their first language, compared to 22.7 million isiZulu first language speakers, 16 million isiXhosa first language speakers and 13.5 million first language Africans speakers (See Figure 2).

The enrolment for Afrikaans at undergraduate level has experienced an overall steady, albeit small, increase over the years. This may be explained by the fact that Afrikaans remains the second compulsory language in most schools throughout the country and that students requiring a second language as part of their degree are therefore likely to choose Afrikaans. The sum of the nine indigenous languages is barely comparable to Afrikaans since 2005. More striking is its plummeting trend evident from 1999, making the indigenous languages the largest contributor to the declining undergraduate enrolment of the discipline languages, linguistics and literature ${ }^{3}$ as a whole (Pillay and Yu 2010). There is a notable increase in enrolment for all languages since 2008 but this is followed by a tapering off and even mild decline in all languages from 2011, with a small bounce back in 2012. This trend may be explained in part by the closure of language programmes at some universities in 2010 (Turner 2012).

A racial breakdown of the growth spurt (Figure 3) shows that this has been primarily accounted for by the African students. Our intention here is not to offer any unpacking of the notions of race but to read this data within the broader transformation of the higher education project to increase access to higher education for historically disadvantaged groups. The high starting point for African students may be explained by the limited discipline choice available to African students in apartheid South Africa (Cele 2004). It is arguable, therefore, that the number of African students participating in language study is more 'realistic' in the current context given the vastly increased disciplines available to all South African students. It is possible also that the decreased numbers of all students, especially African students, may partially be explained by the perception that language study does not yield employability or significant economic mobility (Maharasoa and Hay 2001).

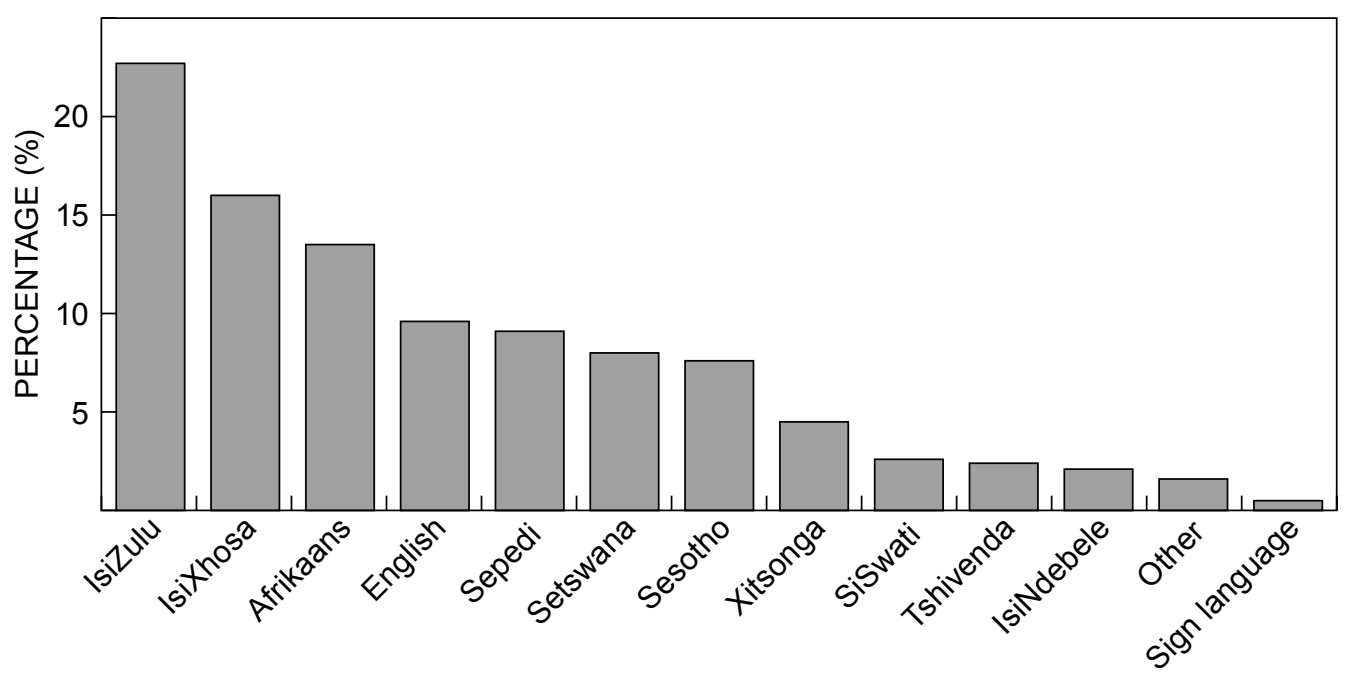

Figure 2: Distribution of the population by first language spoken (percentage). Source: Census 2011 


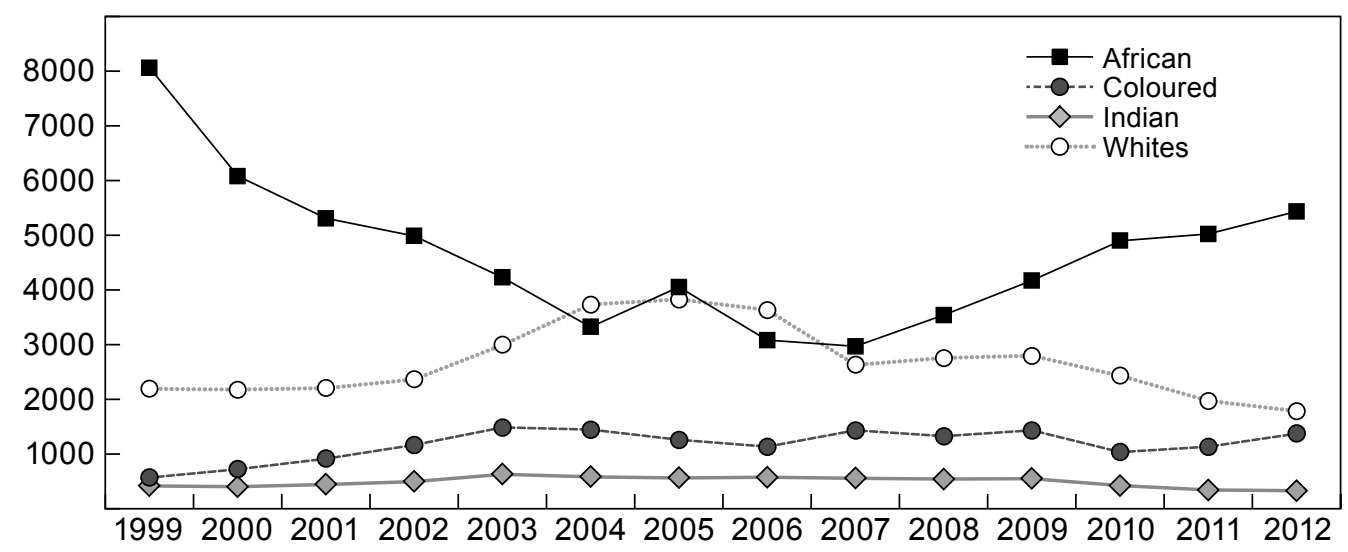

Figure 3: Racial breakdown of undergraduate enrolment for all 11 official languages

Parkinson et al. (2011) and Rudwick and Parmegiani (2013) point to apartheid language policies as a contributory factor to the current undervaluing of African languages. In sum, Bantu education had the effect of limiting proficiency in English, alongside lethargy in developing African languages as a viable language of teaching and learning beyond the meagre requirements of Bantu education. In effect Bantu education had the cumulative outcome of making the African student a linguistic jack of all trades and a master of none. The African teachers, trained though Bantu education, who continue to teach the students who eventually come to universities, invariably pass on this linguistic legacy to the learners in their classrooms.

Using a graduation/enrolment ratio as a crude indication for throughput rate, Figure 4 shows that the throughput rate for all languages, except for indigenous language, has worsened over the period of observation. The most serious decline of throughput rate has occurred in Afrikaans. The lower throughput in Afrikaans may be explained by the higher enrolments in Afrikaans, especially of non-Afrikaans mother tongue speakers (Figure 9) and does not necessarily signal a 'decay' of the language. The rate for indigenous languages, meanwhile, has for most years been among the best throughput rate among the various language groups. This may be explained by relatively low enrolments and the small number of non-mother tongue speakers who enrol in African language programmes (Figure 11). It is also feasible that in a context of increased choices those who enrol in

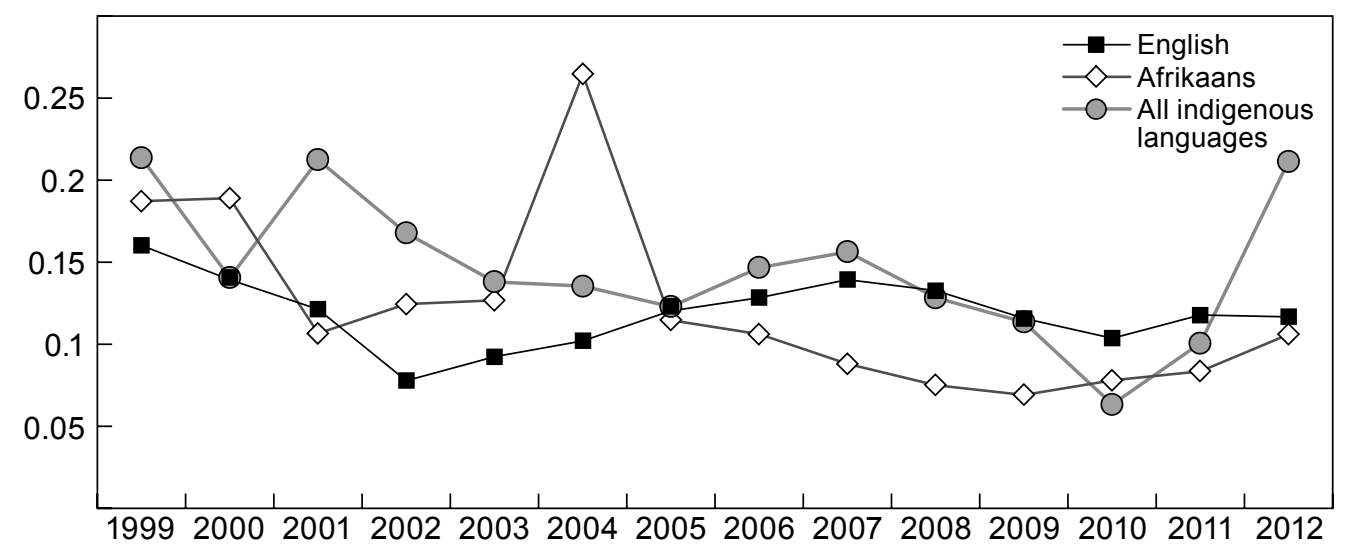

Figure 4: Undergraduate graduation/enrolment ratio for Afrikaans, English and all indigenous languages 
an indigenous language course make deliberate choices, and are more likely to succeed. In other words, this may be a course they want to study and not a course they have to study. This may in part explain the improved throughput rates in the period 2010-2012.

\section{Racial enrolment patterns for Afrikaans, English and all indigenous languages}

The following section reports the language enrolment pattern for different race groups. We plot the trend of enrolment for various languages against racial variables to demonstrate the racial composition of enrolment for each language group. In other words, these figures show who is studying which languages. Two sets of figures are presented here using the following key questions as a guide:

1. What are the most/least popular languages for African/coloured/Indian/white undergraduate students?;

2. Which racial group accounts for the biggest enrolment in Afrikaans, English, and indigenous languages?

We are aware that the data for these two sets of questions are interrelated. However, we report them separately here because the former gives an indication of the preference of language for different racial groups, while the latter indicates the racial profile for each language group.

In 1999, indigenous languages as a sum was the most popular language choice among African students (Figures 5-8). Not surprisingly, such popularity plummeted during 1999/2000, and has declined continuously since 2001, with a small bounce back after 2009. As already explained earlier, this can in part be attributed to the opening up of disciplines available to all students and the perceived low economic returns linked to language study, especially indigenous language study. In 2009 , the total number of African students studying all nine indigenous languages enshrined in the South African Constitution (1996) is marginally higher than African students studying Afrikaans. Turner and Wildsmith-Cromarty (2014) suggest that one explanation for the decline in African languages is the negative attitudes of mother tongue and non-mother tongue speakers towards African languages, mainly attributed to their limited value for economic mobility.

The popularity of Afrikaans among African students seems to have undergone a small yet continuous increase since 2006, explained in part by the dominance of Afrikaans as the second compulsory language in schools throughout the country. In addition, Coetzee-Van Rooy (2012) in a study of student choices with respect to language study in the Vaal triangle, a predominantly Afrikaans-speaking region, also makes the point that Afrikaans is seen as an important language for employability in the region (113). It is feasible that once the goal of the KwaZulu-Natal provincial department of education to make isiZulu the second compulsory language in the province, and given that isiZulu is the first language to $22.7 \%$ of South Africans (Census 2011), the language of increased employability in KZN may indeed be isiZulu in the years to come.

Since the plummeting of indigenous languages in 2000, English has maintained a leading position as the most likely language of choice for African students. Although only $2.9 \%$ of the African population describe themselves as English first language speakers, it remains a popular choice among African students. Despite the overall enrolment in English declining since 1999, Figure 10 shows a noticeable bounce back for 2007 and 2009. As opposed to all the other languages, it is well documented that English remains the primary language of economic and social mobility and its popularity is not under risk.

English has evidently remained the most likely language choice among coloured students too: its popularity has gained momentum since 1999. The popularity of English experienced a decline among coloured students from 2004 to 2009. However, its popularity gained ground again in 2010 . There is also a steady growth of coloured students studying Afrikaans, particularly after 2006 (Figure 9 ). This is not surprising given that over $75 \%$ of the coloured population describe themselves as first language Afrikaans speakers (Census 2011).

English also remains the most likely language of choice for Indian students, similar to coloured students. This is to be expected given that $86 \%$ of the Indian population describe themselves as English first language speakers. However, indigenous languages seem to enjoy greater popularity among Indian students than Afrikaans (Figure 7), different from the coloured students. This, however, 


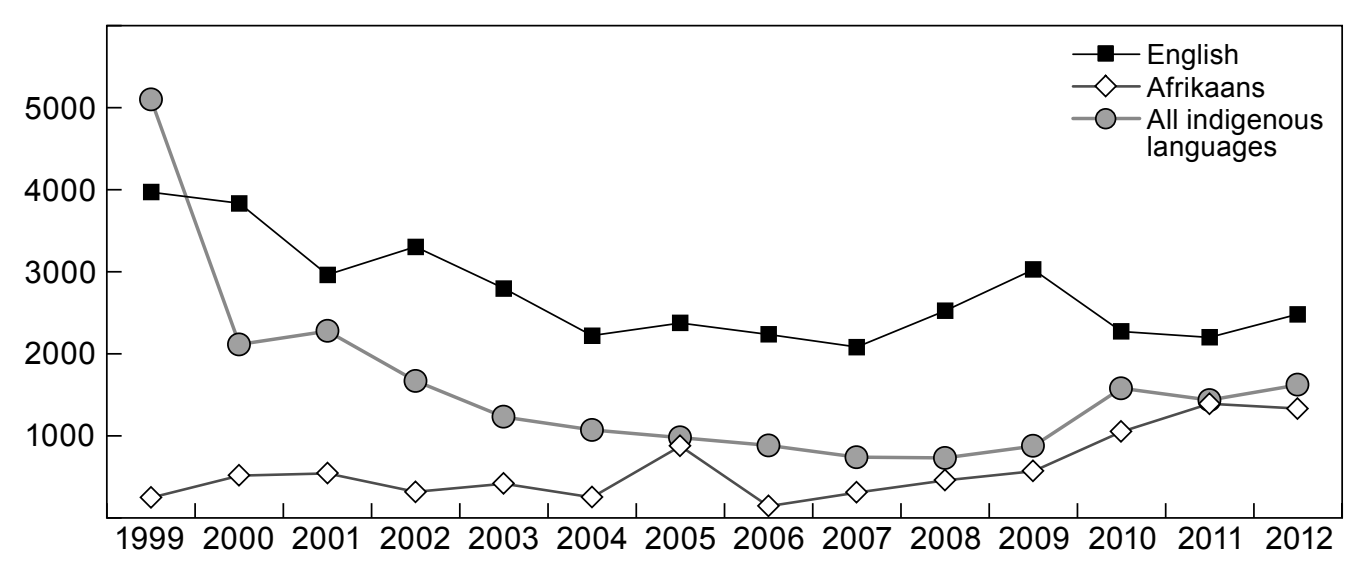

Figure 5: Undergraduate African students' language enrolment patterns

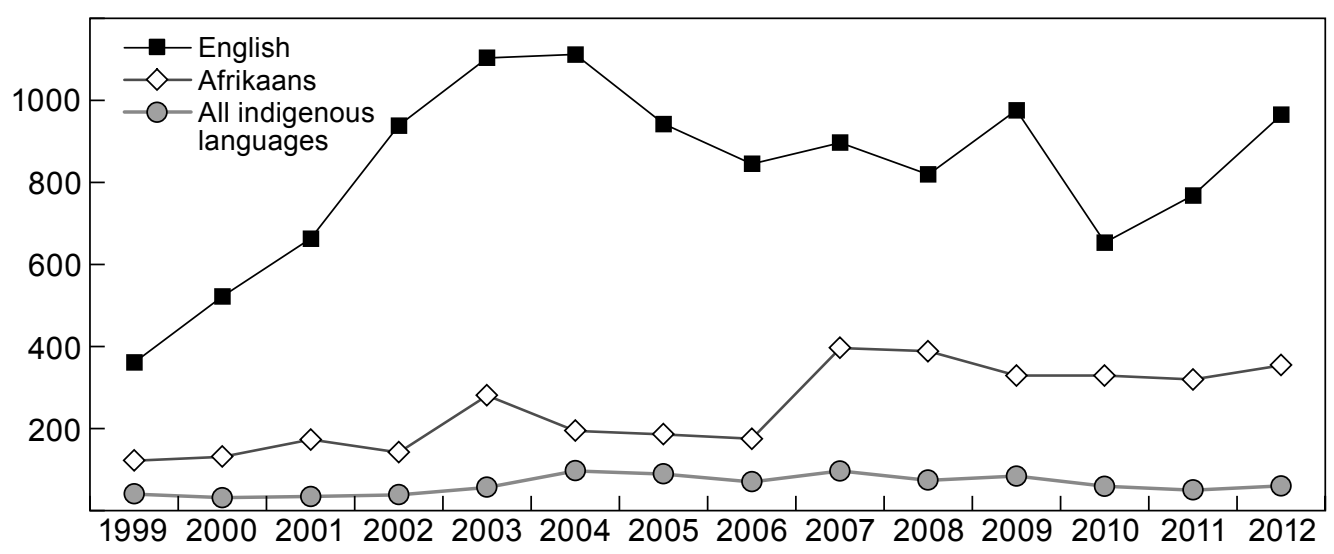

Figure 6: Undergraduate coloured students' language enrolment pattern

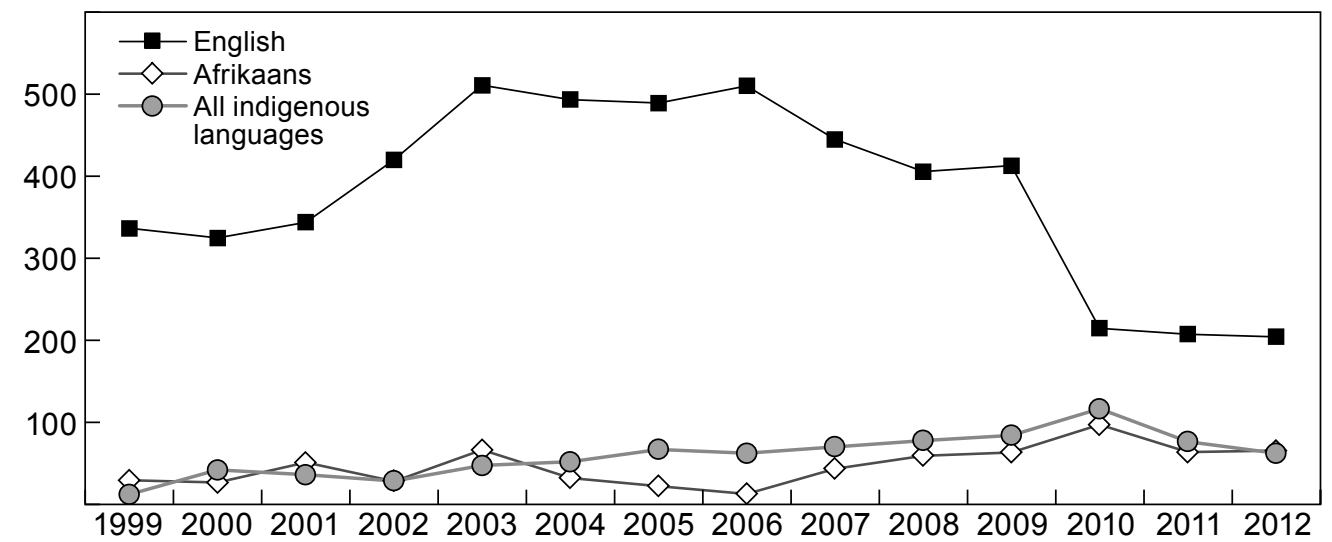

Figure 7: Undergraduate Indian students' language enrolment pattern 


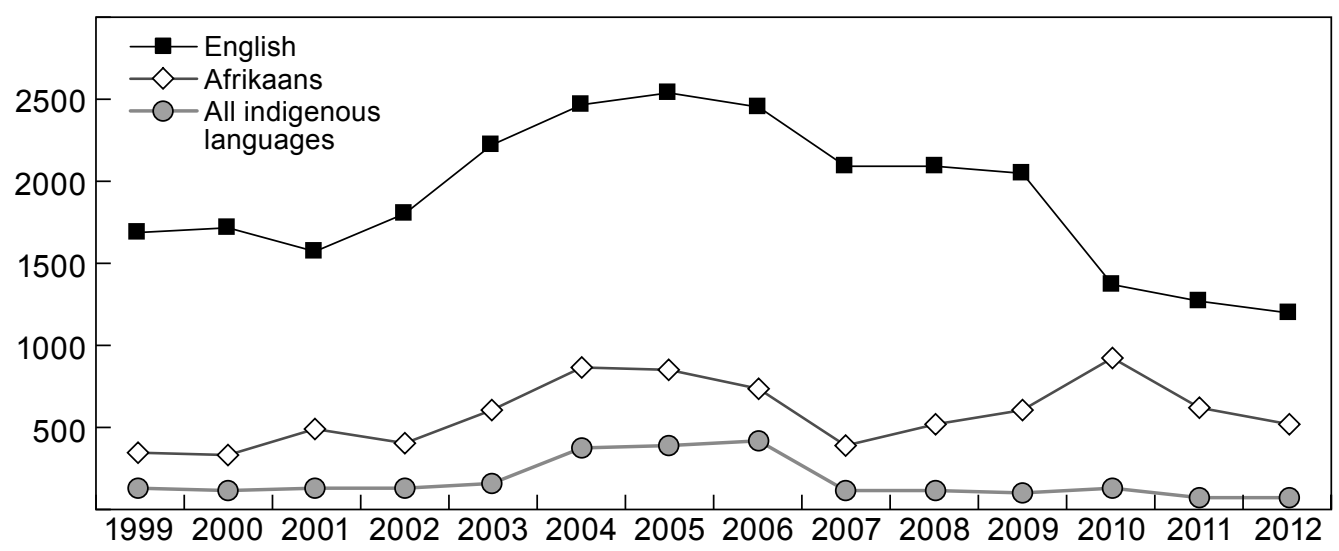

Figure 8: Undergraduate white students' language enrolment

could be due to the fact that Afrikaans is not the first language to as many Indian students as it is to coloured students. Only $4.5 \%$ of the Indian population list Afrikaans as their first language. Although, Indian students do not significantly list any African language as a first language, $1.3 \%$ do list isiZulu as their first language (Census 2011). This may be explained by the fact that the vast majority of the country's Indian population lives in KZN where isiZulu is the dominant indigenous language. IsiZulu is also a valuable language for employability, and economic and social interaction in the province. Most importantly, the active promotion of isiZulu as a regional language by the university in that province and by the Provincial Education Department (PED) has, in all likelihood, contributed to this heartening movement. Indeed, the head of the School of Zulu at the University of KwaZulu-Natal says in a 19 June 2011 Sunday Independent article 'Students keen to learn an African language' (Hawker 2011) that there 'has been an increasing interest in Zulu courses among those who are not mother tongue speakers'. Sadly, Indian students are a small minority in the South African student population and their behaviour with respect to language choices is not likely to make a significant impact on the national linguistic fabric.

English is the most likely language subject for white students too. For unknown reasons, the enrolment for all language subjects for white student seems to have undergone a relatively steady increase until 2004, a decline until 2007, some form of recovery thereafter and a sharper decline in 2010. It is to be noted that Afrikaans is the only language subject that recovered well after 2007, while both English and indigenous languages have experienced a continuous decrease, albeit smaller, from the sharp fall in 2007. Interestingly, white student enrolments display a remarkable similarity of pattern across English, Afrikaans and indigenous languages between 2002 and 2007. This pattern is not replicated in the other race groups and no viable explanation for this could be found at the time of writing.

What follows in Figures 9-11 is a racial profile of Afrikaans, English and the indigenous languages.

It is evident from Figure 9 that, although at different times one race group dominated the other in Afrikaans study at the undergraduate level, white and African students remain the two largest and competing racial groups for this language, with African students marginally outstripping white students in 2005 and again from 2010. This may be explained by the large African student population relative to the white student population (Approximately 320000 and 110000 respectively in 2012). As explained above, the coloured population has increasingly taken up its share in the Afrikaans studying population. From 2009 to 2011 the popularity of Afrikaans shows a sharp increase particularly among African students. Of course the fact that Afrikaans is the compulsory second language in most schools is pertinent, but it is also arguable that Afrikaans is no longer a powerful symbolic tool of oppression as it used to be in the apartheid years. As Cele (2004) argues, Afrikaans is less and less a symbol of colonial power. It is feasible that the once emotional and bloody battles 


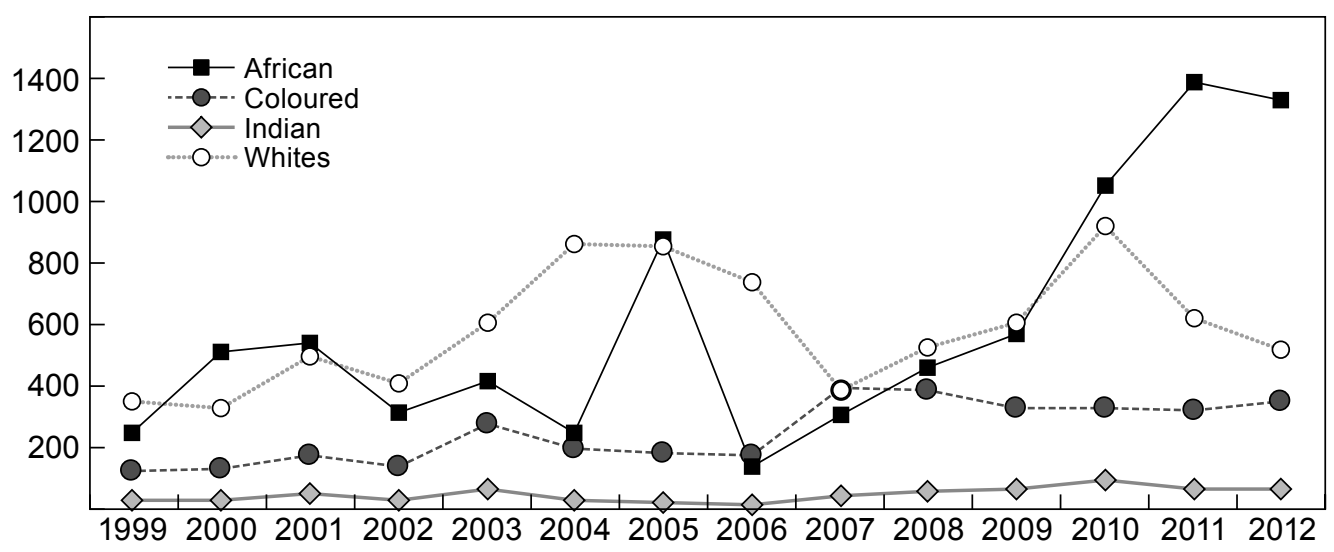

Figure 9: Racial profile of undergraduate graduation for Afrikaans

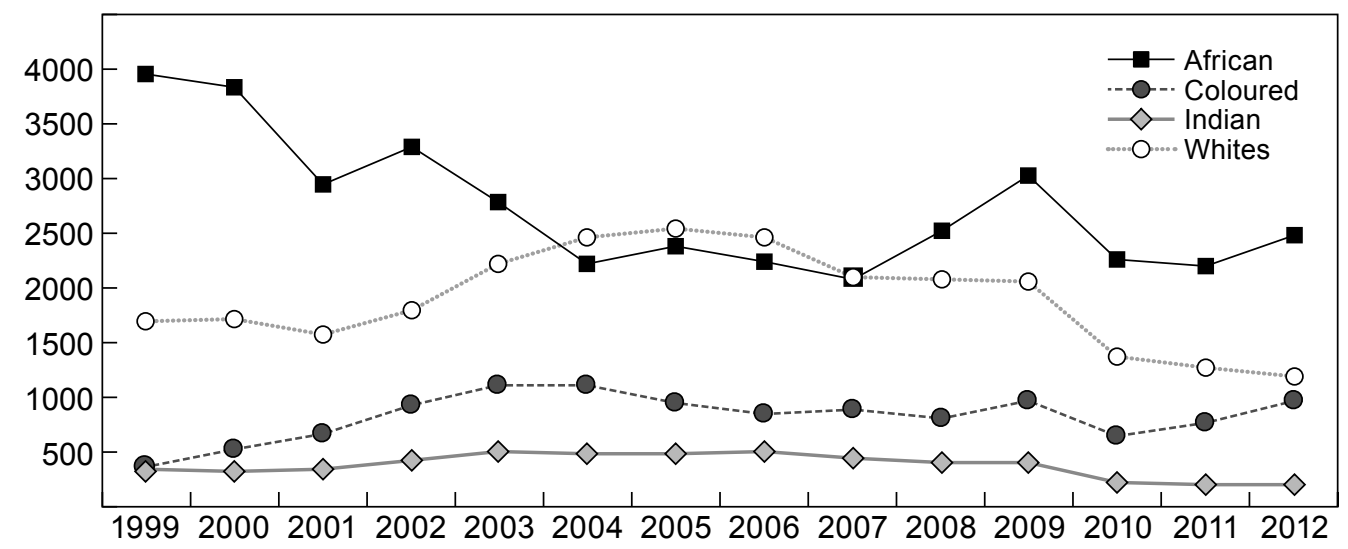

Figure 10: Racial profile of undergraduate enrolment for English

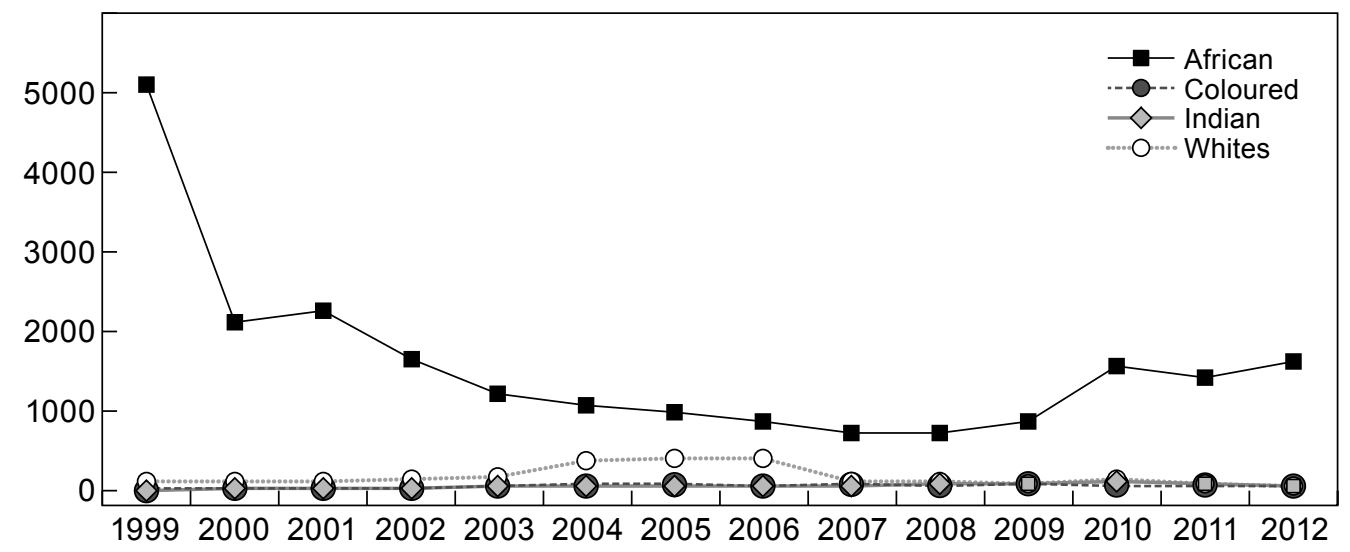

Figure 11: Racial profile of undergraduate enrolment for all nine indigenous languages 
fought against the use of Afrikaans in schools and the oppression associated with Afrikaans is increasing taking its rightful place in history.

African undergraduate enrolment for English has, for most of the time, remained the largest English studying population due mainly to the fact that they constitute, by far, the largest number of students in the higher education system. However, African take up of English as a subject has experienced a steady decrease over the years with a recovery from 2007, followed by a decline again in 2010. White and Indian student enrolment in English has also decreased overall from 1999 to 2012 but coloured student enrolments have more than doubled, albeit from a low base. As discussed earlier, English remains a powerful language and is under no threat of extinction.

It is evident from Figure 11 that Africans remain the single largest racial group that studies any of the nine indigenous languages at undergraduate level. However, there has been a sharp decline in this cohort. There appears to be an increasing interest from white students to study indigenous languages from 2003 to 2006, but such interest seems to have dwindled afterwards. Figure 7 shows a similar increased interest from Indian students but their number is too small to noticeably mark their presence in Figure 11. The dramatic decline in the number of students studying indigenous languages should be sounding every alarm bell. From more than 5000 students in 1999 the number of students studying indigenous languages has dropped to around 1600 in 2012 . This shows a $68 \%$ decrease in little over ten years. When set against the $1542 \%$ increase of African students' population in the whole higher education sector in the same period (316 668 in 2012 versus 124 590 in 1999), it is clear that is a quiet storm about to hit us in the next few years, a storm that could potentially threaten any possibility of the indigenous languages becoming part of the higher education institutional fabric.

\section{Study pattern for individual indigenous languages}

Figure 12 shows the respective trends for undergraduate enrolments for each of the nine indigenous languages. It is clear from this figure that isiZulu, isiXhosa and Sesotho are the indigenous languages most studied at undergraduate level. Given that isiZulu and isiXhosa first language speakers constitute $22.7 \%$ and $16 \%$ of the population respectively, this trend (Figure 2 ) is understandable. Figure 11 indicate that a small number of these students are not native speakers. It is worth noting that although Sesotho first language speakers constitute $7.6 \%$ of the population, and that and Sepedi and Setswana first language speakers are $8 \%$ and $9.1 \%$ respectively, there are more students studying Sesotho than there are Setswana and Sepedi. A factor that may contribute to this scenario is the presence of Sesotho speakers from outside the country, mainly from Lesotho, studying in the country. It is possible also that Sesotho is seen to be have economic currency given that it is a strongly prevalent language in Gauteng, the economic hub of the country (According to Census 2011, Gauteng has the largest non-citizen population of $7.1 \%$, compared to other provinces, as well as the largest absolute number of residents). At the same time, it should be noted that the language popularity rankings have changed slightly over the years: in 1999, isiZulu attracted most students, followed closely by Sesotho, and at a distance by isiXhosa; while in 2009, isiZulu remained the largest language subject among indigenous languages. However, the popularity of Sesotho has declined and is now ranked third, trending at a distance after isiXhosa. All other indigenous languages were studied by less than 100 students in the whole country in 2012. Undergraduate enrolment for Setswana experienced a surge from 2003 to 2006, but the growth was not sustained. It is also to be noted that undergraduate enrolment for isiNdebele has never been more than 10 .

\section{Conclusion}

The data offered here show some clear patterns. The first is that English has remained the language of choice for all race groups in the country for the period under study. This is verified by the ASSAf Report (2010: 65) which indicates that English far outstrips all the other languages. In so saying, we do not wish to accord English an ontology that abstracts it from its contextual existence and perpetuation. Indeed in 2001 and 2010 the drop in English (Figure 1) is matched by a similar increase in other languages. However, on the whole the data speaks volubly to the argument made by Cele (2004) that the 'chapter of lament' with respect to English being the language of the colonial 


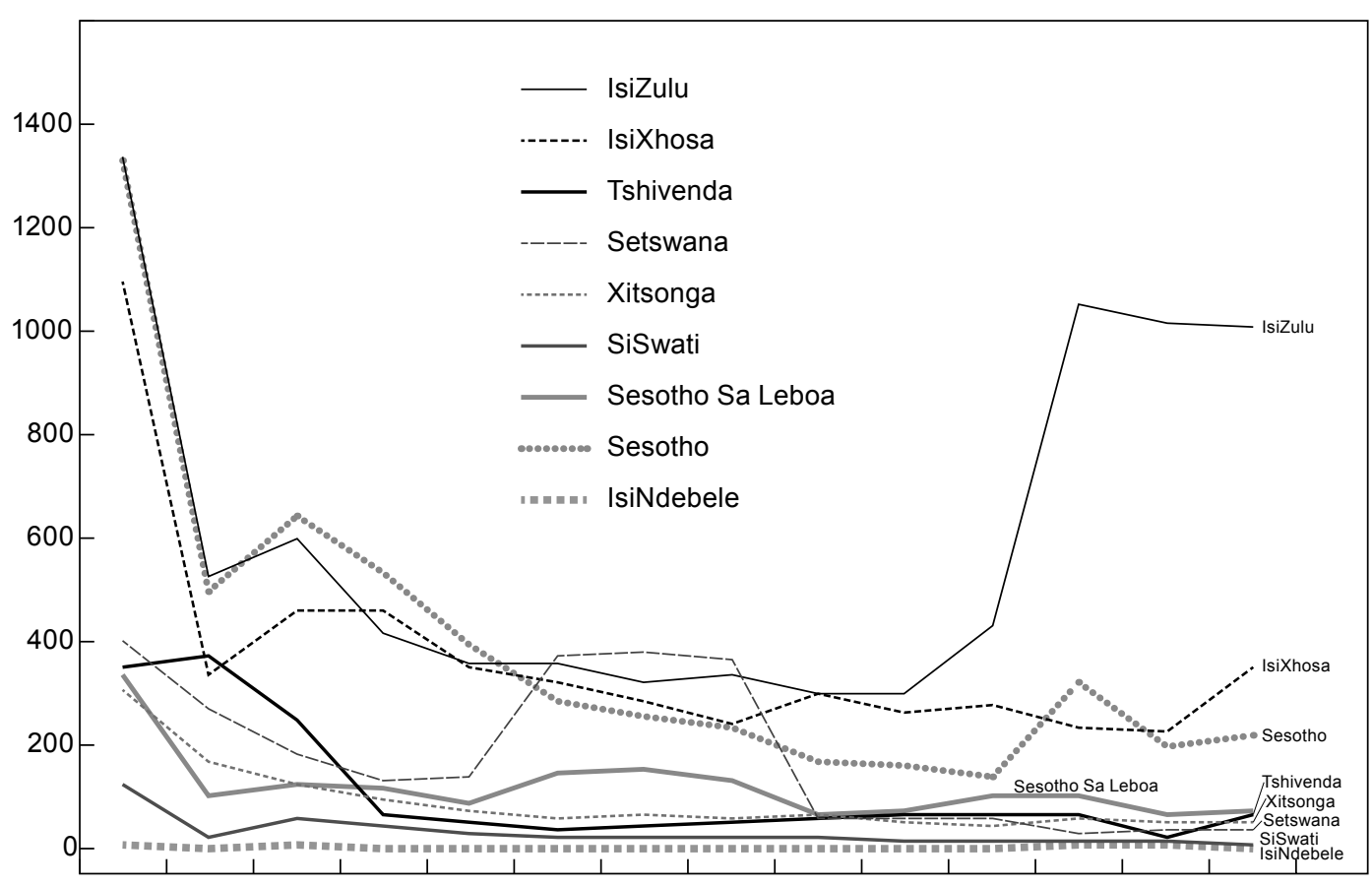

19992000200120022003200420052006200720082009201020112012

Figure 12: Undergraduate enrolment numbers for individual indigenous languages

oppressor needs to be 'archived and kept subconsciously at the back of our minds' (2004: 4). The power of English as the language of economic, social and political currency no doubt exceeds its repressive history.

The data shows that African student enrolment in English remains the largest English studying population. In addition to it being the language of socio-economic power, this may be explained by the legacy of African enrolment in higher education being primarily in the humanities. This trend has changed significantly since 1994 (Yu and Pillay 2011) and African enrolment in higher education is now more evenly spread, despite clustering in some disciplines (CHE 2009). In the main, the unequivocal popularity of English is a clear signal for policy makers both at the basic and higher education levels, mainly because its popularity threatens to overshadow all the indigenous languages. In sum, policy should focus not on English, which is secure, but on the languages under threat.

A second unsurprising, visible pattern is that African students remain the single largest racial group that studies any of the nine indigenous languages. However, we find the marginal increased interest from white and Indian students in the indigenous languages of value. Yet this is too small to be significant.

Finally, and most importantly, the data presented here appears to be sounding increasingly loud alarm bells with respect to the status of indigenous languages in South Africa. There is little doubt that its popularity measured in enrolments and graduations is in decline. Yet many higher education institutions in the country seem to be turning a deaf ear to this. Aside from UKZN and UCT, and to some extent Rhodes University, which asserts an acquisition perspective in policy and implementation through ensuring that the learning of an indigenous language in programmes that require extensive engagement with the communities they serve is compulsory, there appears to be a disturbing silence from the other major higher education institutions with respect to the role of the institution in promoting and asserting the value of indigenous languages. In drawing on Beukes (2009), Turner (2012) makes the point that 'negative attitudes towards the value of African languages, 
as well as the lack of knowledge about the value of these languages as languages of learning and teaching cannot change markedly without a dedicated plan of action and focused strategies'.

Turner's (2012) point above is echoed by Balfour (2010), who says that without visible commitment to the development of indigenous languages, visible damage occurs. In concurring with both Turner and Balfour, we argue that a visible linguistic storm is brewing, but higher education intuitions, with the exception of a few, are paying scant attention to the looming crisis. We endorse Cele's (2004) argument that waiting for languages to be 'developed' makes little sense. The path taken by UKZN and UCT show that fluency in an indigenous language with the aim of engaging with a wider social community has undeniable political, economic and social value. Indeed, this logic is evident in Brand's (2003) argument for a multilingual academy. Yet, other significant players in the higher education landscape remain silent. In providing numeric shape to the anecdotal conversations about the slow death of indigenous languages, together with the growing benefits of a concerted implementation plan for the promotion of indigenous languages, we hope that higher education institutions will sit up and take note of the approaching storm on our doorsteps.

\section{Notes \\ 1 Available at: web.uct.ac.za/depts/ched/adp/ldg/senate_multilingualism.pdf \\ 2 Available at: www.ufs.ac.za/dl/userfiles/Documents/00000/335_eng.pdf \\ 3 Discipline descriptor from the HEMIS database.}

\section{References}

Academy of Science of South Africa (ASSAf). 2010. Consensus Study on the State of the Humanities in South Africa: Status, Prospects and Strategies. Pretoria: ASSAF.

Balfour RJ. 2007. University language policies, internationalism, multilingualism, and language development in South Africa and the UK. Cambridge Journal of Education 37(1): 35-49.

Balfour RJ. 2010. Mind the gaps: higher education language policies, the national curriculum and language research. The Language Learning Journal 38(3): 293-305.

Beukes AM. 2009. Language policy incongruity and African languages in post-apartheid South Africa. Language matters: studies in the African Languages of Africa 40(1): 35-55.

Brand G. 2003. Imagining a multilingual academy: rethinking language in higher education. South African Journal of Higher Education 17(3): 26-35.

Cele N. 2004. 'Equity of access' and equity of outcomes' challenged by language policy, politics and practice in South African higher education: the myth of language equality in education. South African Journal of Higher Education 18(1): 38-56.

Coetzee-van Rooy S. 2012. Flourishing functional multilingualism: evidence from language repertoires in the Vaal Triangle Region. International Journal of the Sociology of Language 281: 87-119.

Council on Higher Education (CHE). 2009. Higher education monitor postgraduate studies in Africa: a statistical profile. Pretoria: CHE.

Foley A. 2002. South African education and the dilemmas of multilingualism. English Academy Review 19 (4): 51-64.

Gao F. 2009. Language and power: Korean-Chinese students' language attitude and practice. Journal of Multilingual and Multicultural Development 30(6): 525-534.

Hill LB. 2009. The decline of academic bilingualism in South Africa: a case study. Language policy 8: 327-349.

Leibowitz B, van Deventer I. 2007. Evaluation of a South African university's language policy. Education as Change 11(1): 87-110.

Madiba M. 2013. Multilingual education in South African universities: policies, pedagogy and practicality. Linguistics and Education 24: 385-395.

Maharasoa M, Hay D. 2001. Higher education and graduate employment in South Africa. Quality in Higher Education 7(2): 139-147.

Marginson S. 2011. Higher Education and Public Good. Higher Education Quarterly 65(4): 411-433. Moodley D. 2010. Bilingualism at the University of KwaZulu-Natal. Nordic Journal of African Studies 18: 22-72. 
Mwelwa J, Spencer B. 2013. A bilingual (Bemba/English) teaching resource: realizing agency from below through teaching materials designed to challenge the hegemony of English. Language Matters: studies in the languages of Africa 44(3): 51-68.

Narismulu P. 2001. Developing curriculum and audience: the case of the module 'Language and Power'. Perspectives in Education 19(2): 49-66.

Ndimande-Hlongwa N, Balfour RJ, Mkhize N, Engelbrecht C. 2010. Progress and challenges for language policy implementation at the University of KwaZulu-Natal. The Language Learning Journal 38(3): 347-357.

Hawker D. 2011. Students keen to learn an African language. Sunday Independent. Available at: www.iol.co.za/news/south-africa/students-keen-to-learn-an-african-language-1.1085115\#. UwyaQlcaJzk. [Accessed on 7 April 2015].

Parkinson J, Baba S, Mackay J. 2011. Language support for the learning a second language: What can the Malaysian example offer South Africa. Language Matters: studies in the languages of Africa 42(1): 69-82.

Pillay V, Yu K. 2010. The state of Humanities in post-apartheid South Africa-a quantitative Story. South African Journal of Higher Education 24(4): 602-615.

Rudwick S, Parmegiani A. 2013. Divided loyalties: Zulu vis-à-vis English at the University of KwaZuluNatal. Language Matters: studies in the languages of Africa 44(3): 89-107.

Turner NS. 2012. African languages as compulsory course in KwaZulu-Natal: illusory initiative or inspired intervention? Per Linguam 28(2): 28-45.

Turner N, Wildsmith-Cromarty R. 2014. Challenges to the implementation of bilingual/multilingual language policies at tertiary institutions in South Africa (1995-2012). Language Matters: studies in the languages of Africa 45(3): 295-312.

Van der Walt C, Brink C. 2005. Multilingual universities: a national and international overview. South African Journal of Higher Education 19(4): 822-851.

Yu K, Pillay V. 2011. Tracking enrolments and graduations in humanities education in South Africa: Are we in crisis? South African Journal of Higher Education 25(6): 1219-1232. 